\title{
Moral Reasoning in Children with Focal Brain Insults to Frontotemporal Regions
}

\author{
V. Chiasson, ${ }^{1,2}$ L. Elkaim, ${ }^{3}$ A. G. Weil, ${ }^{3}$ L. Crevier $^{3}$ and M. H. Beauchamp ${ }^{1,2}$ \\ ${ }^{1}$ Department of Psychology, University of Montreal, Montreal, Canada \\ ${ }^{2}$ Sainte-Justine Hospital Research Center, Montreal, Canada \\ ${ }^{3}$ Neurosurgery Service, Department of Surgery, Sainte-Justine Hospital, University of Montreal, Montreal, \\ Canada
}

\begin{abstract}
Neuroscientific evidence indicates that human social functioning is supported by a distributed network of frontal and temporal brain regions that undergoes significant development during childhood and adolescence. Clinical studies of individuals with early brain insults (EBI) to frontotemporal regions suggest that such lesions may interfere with the maturation of sociocognitive skills and lead to increased sociobehavioural problems. However, little attention has focussed on the direct assessment of sociocognitive skills, such as moral reasoning, following focal EBI. In the present study, the performance of 15 patients with focal EBI (8-16 years) was compared to that of 15 demographically matched controls on basic neuropsychological measures (IQ and executive functions), sociocognitive tasks (moral reasoning, moral decision-making and empathy) and parent reports of sociobehavioural problems and social adaptive skills. Patients with focal EBI had significantly lower levels of moral reasoning maturity, moral decision-making, and empathy than their matched controls, but did not differ on more general measures of cognition. Their parents also reported increased sociobehavioural problems. These findings suggest that focal EBI to frontotemporal regions can result in reduced sociocognitive capacities, more specifically moral reasoning, and increased vulnerability to sociobehavioural problems.
\end{abstract}

Keywords: Moral reasoning, Social Cognition, Focal Lesions, Early Brain Insult

\section{Introduction}

The way in which an individual understands and interacts with the social world is represented in the functions of the social brain, a set of wideranging neural networks involved in the perception of social cues and the regulation of socioemotional functioning and behaviour (Cacioppo \& Decety, 2011; Frith \& Frith, 2010). The social brain includes frontal, temporal and limbic regions, and parts of the basal ganglia (Adolphs, 2009; Beauchamp \& Anderson, 2010). The perceptual and cognitive functions that support this system are collectively called social cognition and underpin more global social development and competence (Beauchamp \& Anderson, 2010). The development of the social brain is a dynamic process that undergoes significant and protracted evolution from childhood to early adulthood (Blakemore, 2008; Burnett \& Blakemore, 2009). This maturation involves a complex and dynamic set of genetically guided processes by which neural structures, particularly in frontotemporolimbic areas, interact with the environment to shape the emergence of emotional and social behaviour (Bigler et al., 2013; Blakemore \& Frith, 2004; Jernigan, Baare, Stiles, \& Madsen, 2011; Stiles \& Jernigan, 2010). As a

Address for correspondence: Miriam H. Beauchamp, Department of Psychology, University of Montreal, C.P 6128, Succ. Centre-Ville, Montreal, Quebec, Canada, H3C 3J7. Tel: 1-514-343-6111, ext: 35171; Fax: 1-514-343-2285.

E-mail: miriam.beauchamp@umontreal.ca 
result, the developing social brain is vulnerable to early insult, which has the potential to disrupt neural maturation, as well as the development of associated socio-cognitive skills and may result in changes to expected trajectories of social development across childhood and adolescence.

It has been suggested that the nature of brain pathology (i.e. focal vs. diffuse insult) may play a particularly important role in mediating outcome after EBI (V. Anderson, Spencer-Smith, \& Wood, 2011). Traditionally, it has been argued that when early damage is focal (e.g. tumor, stroke, focal dysplasia, etc.), there is a capacity for neuronal reorganisation and relatively better functional outcome (Aram \& Ekelman, 1986; Stiles, Reilly, Paul, \& Moses, 2005). In contrast, sustaining a generalised cerebral insult (e.g. traumatic brain injury (TBI), cerebral infection, etc.) is associated with slower recovery and more severe impairments (Anderson, Catroppa, Morse, Haritou, \& Rosenfeld, 2005). In keeping with this, studies on social outcomes after TBI in youth have shown that children and adolescent survivors have an elevated risk of social dysfunction, with consistent difficulties identified for social adjustment and social cognition (Anderson, Godfrey, Rosenfeld, \& Catroppa, 2012; Rosema, Crowe, \& Anderson, 2012; Yeates et al., 2004). Amongst the sociocognitive functions affected are emotion recognition (Tonks, Williams, Frampton, Yates, \& Slater, 2007; Turkstra, McDonald, \& DePompei, 2001), theory of mind (Dennis et al., 2012; Snodgrass \& Knott, 2006; Turkstra, Dixon, \& Baker, 2004), social problem-solving (Ganesalingam, Yeates, Sanson, \& Anderson, 2007) and moral reasoning (MR) (Beauchamp, Dooley, \& Anderson, 2013; Dooley, Beauchamp, \& Anderson, 2010). Whilst there is mounting evidence that trauma-induced neuropathology may influence social behaviour following early TBI, it is less clear how early lesions of focal aetiology impact social behaviour and social cognition. The paucity of research in this area may be attributable to several factors: (1) Data describing the impact of focal EBI on social functioning comes mainly from case studies with few group studies conducted; (2) Much of our knowledge on outcomes after focal EBI relies on aspects of general cognition (intelligence, language, motor function, etc.) and (3) As mentioned above, it is thought that focal injuries generally have better prognosis than diffuse injuries.

Existing reports of focal EBI outcome on more general aspects of cognition provide some information on the recovery of the immature brain after focal lesions. Residual language deficits following early left or right hemisphere lesions appear to be more subtle in children compared to adults (Bates et al., 1997; Chilosi et al., 2008), whereas the development of visuospatial function following early focal brain damage corresponds more closely to findings obtained in adults with similar lesions (Stiles et al., 2008). Regarding intellectual functioning, children with focal brain lesions generally perform below expected norms, but still within the average range (Carey, Barakat, Foley, Gyato, \& Phillips, 2001; Hetherington, Tuff, Anderson, Miles, \& deVeber, 2005; Hogan, Kirkham, \& Isaacs, 2000). Duval et al. (2008) conducted a study in 240 patients with focal brain lesions and found that lower intellectual quotient (IQ) was associated with early occurring lesions rather than those sustained later in life, although scores remained in the average range. More specifically, IQ change over time was negative when the lesions occurred early in childhood, whereas adult onset cases benefited from recovery over time with age, thus highlighting the vulnerability of the developing brain to early insult.

The literature on social outcomes after focal EBI consists mostly of reports of individual cases presenting with prefrontal damage, often assessed in adulthood, or of aetiology-specific studies of global social competence after particular medical conditions. These reports suggest that early onset lesions to the prefrontal cortex could lead to severe sociobehavioural problems (Anderson, Bechara, Damasio, Tranel, \& Damasio, 1999; Bahia et al., 2013; Boes et al., 2011; Eslinger, Flaherty-Craig, \& Benton, 2004). A review of 31 studies on psychosocial adjustment in survivors of childhood brain tumours also suggests that these patients are at risk for deficits in social competence, defined as a multidimensional construct comprised of adaptive behaviour, social skills, and peer acceptance (Fuemmeler, Elkin, \& Mullins, 2002). Studies on paediatric stroke also document poorer social functioning following childhood ischemic damage (Anderson et al., 2014; Galvin, Hewish, Rice, \& Mackay, 2011; Lo et al., 2014). In a large-scale study of 147 children with focal EBI of various aetiologies including developmental, ischemic, neuroplastic, traumatic and infective brain lesions, Greenham, Spencer-Smith, Anderson, Coleman, and Anderson (2010) reported that children sustaining these types of lesions were at high risk for social impairment, according to teachers' reports. Interestingly, lesion characteristics (location and laterality) were not predictive of social outcomes.

Despite recognition that focal EBI is associated with an elevated risk of global social dysfunction, the underlying causes are not fully understood. It seems likely that the presence of deficits in one or a number of sociocognitive functions may contribute to putative social impairments. Findings in 
this regard emerge from a case series of individuals with early prefrontal damage, which reports that social impairments are associated with deficits in executive functions, failure to acquire complex social knowledge and lower levels of empathy (Eslinger et al., 2004). However, some of the patients in that study were tested during adulthood, had trauma-induced pathology, and formal testing of social cognition was limited or indirectly studied.

The recent description of heuristic models of social development have sparked interest in creating tools to assess social cognition in clinical populations with the aim of identifying the underpinnings of global sociobehavioural problems (Beauchamp \& Anderson, 2010; Yeates et al., 2007). Moral reasoning (MR) is a sociocognitive function that is thought to play an important role in social competence and has been understudied in neurological populations. MR is defined as how individuals think about moral emotions and conventions that govern social interactions in their everyday lives (Haidt, 2001). It is now widely accepted that MR is driven by distinct neural networks that overlap with the social brain and include frontotemporolimbic regions (Greene, Nystrom, Engell, Darley, \& Cohen, 2004; Sevinc \& Spreng, 2014). Studies from developmental psychology suggest that MR is acquired through stages starting from an ego-oriented morality to a broader, society-oriented perspective (Gibbs, 2010; Turiel, 1983). The development of MR is thus potentially vulnerable to disruption in cognitive growth and brain function, such as in focal EBI. In non-injured children, important links exist between MR, empathy, externalising behaviour and social adjustment which suggest that poorer MR and empathy are associated with juvenile delinquency (Jolliffe \& Farrington, 2004; Raaijmakers, Engels, \& Van Hoof, 2005; Schonert-Reichl, 1999; Vera-Estay, Beauchamp, \& Dooley, 2014; Vera-Estay, Seni, Champagne, \& Beauchamp, 2016). MR has also been found to be associated with several executive functions, including cognitive flexibility, inhibition and verbal fluency (Vera-Estay, Beauchamp, \& Dooley, 2014; Vera-Estay, Seni, Champagne, \& Beauchamp, 2016).

Despite these associations, studies investigating MR in focal EBI are scarce. Initial evidence of moral impairment after focal EBI emerges from three case studies of patients with prefrontal lobe damage who displayed less developmentally mature levels of MR (Anderson et al., 1999; Boes et al., 2011; Grattan \& Eslinger, 1992). In these studies, MR was assessed during adulthood using Kohlberg's Moral Judgment Interview (Colby \& Kohlberg, 1987), a semi-structured interview that presents extreme moral dilemmas. Whilst other in- dications of moral impairments after focal lesions are primarily anecdotal, these studies provide the groundwork for further exploration of MR in focal EBI. To our knowledge, only one study so far has examined the direct, quantitative effect of focal EBI on MR in a group of paediatric patients, reporting that 16 children with focal frontal lesions had lower levels of MR and poorer adaptive behaviour ratings than controls on a paper-pencil questionnaire (Couper, Jacobs, \& Anderson, 2002).

The goals of the present study were therefore to (1) investigate social cognition, social behaviour and social adaptive skills in a group of children and adolescents with focal EBI. It was expected that these individuals would perform more poorly than their typically developing peers on measures of MR (MR maturity, moral decision-making) and empathy, display more sociobehavioural problems and have poorer social adaptive skills and (2) explore the links between social cognition (MR maturity, moral decision-making and empathy) and more general cognitive measures such as IQ and executive functioning (cognitive flexibility), as well as social behaviour in the focal EBI group. It was expected that better sociocognitive skills would be associated with fewer sociobehavioural problems and better social adaptive skills. In line with current literature in moral development (VeraEstay et al., 2014), it was also expected that IQ and cognitive flexibility would be positively correlated with MR maturity. We sought to meet these goals by using a novel visual MR measure that is based on an ecological approach and is adapted for children and adolescents, the Socio-Moral Reasoning Aptitude Level Task (So-Moral), and by studying a group of patients with focal frontal or temporal lesions to reflect the fact that the social brain is subsumed by both frontal and extra-frontal regions.

\section{Methods}

\section{Participants}

Thirty children and adolescents (aged 8-16 years) participated in the study. The clinical sample consisted of 15 children (10 males, 5 females) with focal frontal or temporal lobe lesions identified by magnetic resonance imaging (MRI). These children were recruited from the neurosurgery department at a tertiary urban paediatric hospital. To meet the selection criteria for the study, children were required to be fluent in English or French, be clinically stable (e.g., patients with severe or hard to control epilepsy were not included), and to have documented evidence of a focal lesion identified within frontal or temporal areas (e.g. arterioveinous malformation rupture, tumor, cerebral 
TABLE 1

Characteristics of the Focal EBI Patients and their Scores on the So-Moral

\begin{tabular}{|c|c|c|c|c|c|c|c|c|c|c|}
\hline \multirow[b]{2}{*}{ Patient } & \multirow[b]{2}{*}{ Sex } & \multirow[b]{2}{*}{ Age } & \multirow[b]{2}{*}{ Aetiology } & \multicolumn{3}{|c|}{ Lesion description } & \multirow{2}{*}{$\begin{array}{l}\text { Time since } \\
\text { diagnosis }^{1}\end{array}$} & \multirow[b]{2}{*}{ Seizures } & \multirow[b]{2}{*}{ MR Maturity } & \multirow[b]{2}{*}{ MR stage } \\
\hline & & & & Side & Lobe & Location & & & & \\
\hline A & M & 12 & $\mathrm{AVM}$ & Right & Frontal & IFG & 41 & No & 24.0 & 2 \\
\hline B & $\mathrm{F}$ & 13 & AVM & Right & Frontal & MFG, IFG & 11 & No & 26.5 & 3 \\
\hline C & M & 13 & Tumor & Left & Temporal & MTG, ITG & 77 & No & 22.5 & 2 \\
\hline D & M & 13 & Cyst & Left & Frontal & ACG & 12 & Yes & 19.5 & 2 \\
\hline$E$ & M & 13 & AVM & Left & Fontal & OFG & 32 & No & 24.5 & 2 \\
\hline$F$ & $\mathrm{~F}$ & 16 & Tumor & Left & Frontal & IFG & 98 & Yes & 36.5 & 4 \\
\hline G & M & 11 & Tumor & Left & Temporal & STG, MTG & 75 & No & 17.0 & 2 \\
\hline $\mathrm{H}$ & M & 13 & Tumor & Right & Temporal & MTG, ITG & 54 & Yes & 20.5 & 2 \\
\hline l & $\mathrm{F}$ & 16 & Tumor & Left & Temporal & MTG, ITG & 36 & Yes & 33.0 & 3 \\
\hline J & M & 11 & Cyst & Left & Temporal & STG, MTG & 83 & Yes & 20.5 & 2 \\
\hline K & $\mathrm{F}$ & 8 & Cavernoma & Right & Frontal & SFG & 68 & No & 13.5 & 1 \\
\hline L & $\mathrm{F}$ & 11 & Tumor & Left & Temporal & ITG & 15 & No & 31.0 & 3 \\
\hline M & M & 16 & Tumor & Left & Frontal & MFG, IFG & 96 & Yes & 20.0 & 2 \\
\hline$N$ & M & 11 & Tumor & Left & Frontal & SFG & 20 & Yes & 23.0 & 2 \\
\hline $\mathrm{O}$ & M & 12 & Cavernoma & Left & Frontal & MFG & 12 & No & 20.5 & 2 \\
\hline
\end{tabular}

1. In months.

Abbreviations: $A V M=$ arteriovenous malformation rupture; IFG = Inferior frontal gyrus; MFG = middle frontal Gyrus; SFG = superior frontal gyrus; OFG = orbital frontal gyrus; $A C G=$ anterior cingulate gyrus; ITG = inferior temporal gyrus; $M T G=$ middle temporal gyrus; STG = superior temporal gyrus; $M R=$ moral reasoning.

cyst, cavernoma, etc.). Children were excluded if they had evidence of diffuse injury. Seven patients had surgical resection and they were all seen at least 6 months post-operatively to minimise acute recovery effects. See Table 1 for the lesion characteristics of the Focal EBI group and Figure 1 for examples of focal neuropathology identified via MRI. Presence of seizure history was recorded since it is associated with poorer social outcomes (Greenham et al., 2010). Fifteen control participants (10 males, 5 females) were recruited from a healthy participant database. These controls were attending local elementary and high schools. They were individually matched to clinical participants on sex, age ( \pm 12 months) and parental education. Controls were excluded if they had any history of intellectual disability or developmental, psychiatric or neurological disturbance.

\section{Measures}

Demographic and developmental variables: Demographic and developmental information was collected via an in-house questionnaire completed by parents and pertaining to their child's medical, developmental and social history.

Intellectual functioning: Participants completed the Vocabulary and Matrix Reasoning sub- tests of the Wechsler Abbreviated Scale of Intelligence (WASI, Wechsler, 1999), to provide an estimate of general intellectual ability (Full Scale IQ, FSIQ, $M=100, S D=15$ ). The WASI has adequate internal consistency $(\alpha=.93)$, test-retest reliability $(r=.87)$ and concurrent validity $(r=$ .87) (Garland, 2005).

Executive functioning: Participants completed the Trail Making Test from the Delis-Kaplan Executive Function System (D-KEFS, Delis, Kaplan, \& Kramer, 2001) as a measure of cognitive flexibility. The Number-Letter sequencing versus NumberLetter switching contrast score was used in analyses (range $1-19, M=10, S D=3$ ).

Moral reasoning: The Socio-Moral Reasoning Aptitude Level Task (So-Moral, Beauchamp et al., 2013; Dooley et al., 2010; Vera-Estay et al., 2014; 2016) is a self-paced, visual, computer-based task that presents visual moral dilemmas specifically designed for children and adolescents. The task has gender and age specific versions and includes 10 dilemmas. Each dilemma (see example in Figure 2) consists of: an introductory screen presenting the name of the dilemma (e.g. 'wallet'); three separate screens showing first-person perspective pictures of child or adolescent actors in various social scenarios representing a moral conflict (e.g. concerns with justice, welfare/harm and rights) according 


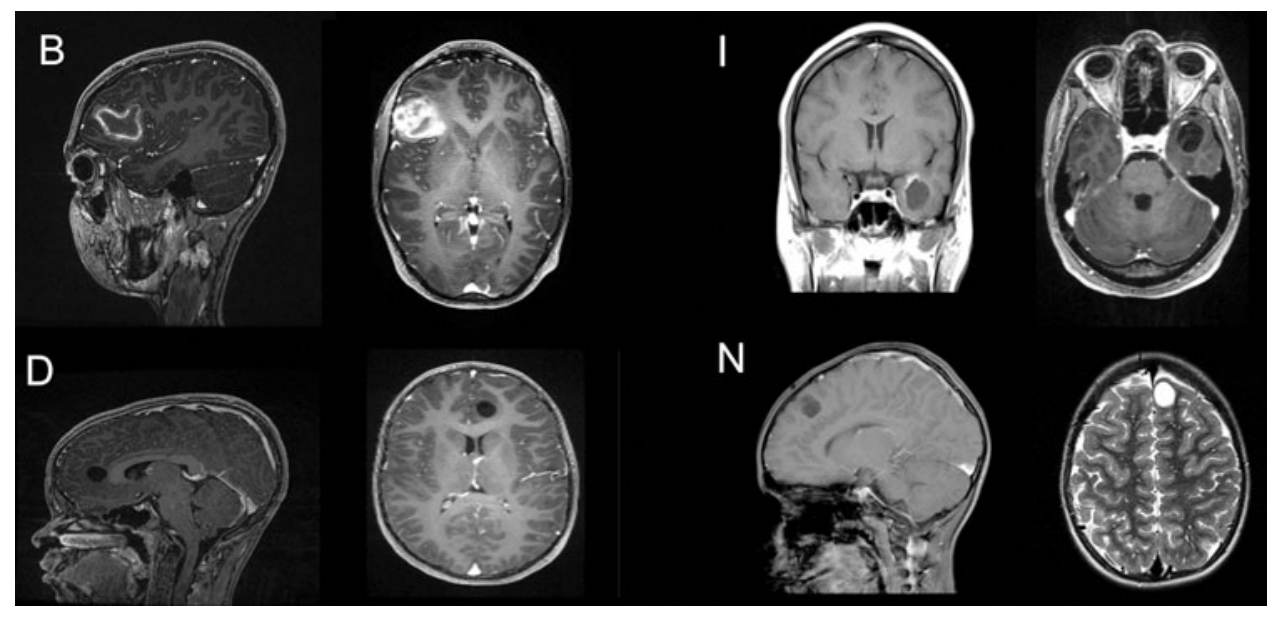

\section{FIGURE 1}

Examples of focal lesions identified in study participants via magnetic resonance imaging. Images are in radiological perspective (subject's left on viewer's right). Sagittal and axial views are presented for Patients $B, D, N$ and coronal and axial views for Patient I. Patient B: Intraparenchymal hemorrhagic lesion in the right ventrolateral prefrontal cortex of the inferior frontal gyrus and parts of the orbitofrontal cortex following AVM rupture. Patient D: Neuro-epithelial cystic lesion in the left anterior cingulate cortex located anterior to the left forceps minor of the genu of the corpus callosum. Patient I: Mixed neuroglial tumor in the left temporopolar cortex (parts of the inferior and middle temporal gyri) anterior to the amygdala. Patient N: Brain tumor (DNET) in the ventromedial prefrontal cortex (anterio-medial portion of the superior frontal gyrus).

to Social Domain Theory (Turiel, 1983); and a final screen presenting a dichotomous decision (e.g. whether or not to engage in a particular action such as stealing from a shop, cheating at a game, etc.).

The aggregate number of morally adapted responses is compiled to obtain a moral decision making score, which ranges from 0 to 10 points. Participants are then asked to provide a justification for the choice they made. Each participant's justification is recorded verbatim and subsequently scored according to a standardised coding system (Beauchamp \& Dooley, 2012) based on the cognitive-developmental approach (Gibbs, 2010; Kohlberg, 1981; Turiel, 1983). Developmental stages of MR have been adapted to fit the social nature of the dilemmas in the So-Moral task and consist of the following: (1) Centrations and authoritarian-based consequences; (2) Egocentric/pragmatic exchanges; (3) Interpersonal focus; (4) Societal regulation; and (5) Societal evaluation (see Table 2). Transition stages $(1.5,2.5$, etc.) are used to account for answers that provide elements of two consecutive reasoning stages. When elements of non-consecutive stages are provided, the response is coded according to the highest schema detected. The MR maturity score ( 0 to 50 points) is obtained by summing the justification scores. The MR maturity score was translated into an overall moral maturity level as follows: Stage 0 $=0-5$ points, Stage $1=6-15$ points, Stage $2=$ 16-25 points, Stage $3=26-35$ points, Stage $4=$ $36-45$ points and Stage $5=46-50$ points. All scoring was done blind to diagnosis and group membership. A second rater independently scored $20 \%$ of the So-Moral justifications. The consistency for

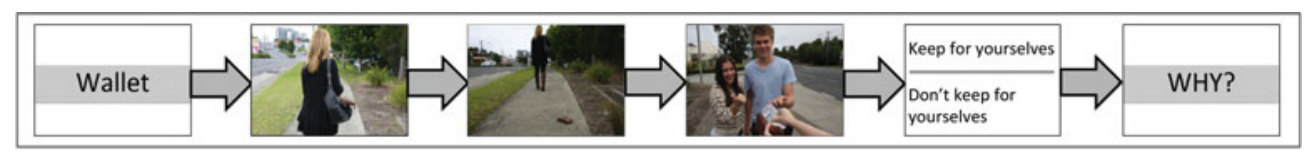

FIGURE 2

Example item from the So-Moral task. 
TABLE 2

Brief Description of So-Moral Coding and Examples

\begin{tabular}{|c|c|c|}
\hline Level & Brief description & Example \\
\hline 1 & $\begin{array}{l}\text { Moral justifications have an egocentric focus, which is based } \\
\text { on obedience to higher authorities and potential } \\
\text { consequences to themselves for their actions (e.g. } \\
\text { punishment). Thinking at this level is inflexible; there is only } \\
\text { one right/wrong way to act. }\end{array}$ & - Because I could go to jail \\
\hline 2 & $\begin{array}{l}\text { Moral justifications are based on a concept of pragmatic deals } \\
\text { or exchanging favours with others (fair deals). Thinking is } \\
\text { more flexible and is determined by context. The correct } \\
\text { option is the one that is right for oneself (self-interest). }\end{array}$ & $\begin{array}{l}\text { - Because I might need his/her help } \\
\text { in the future. }\end{array}$ \\
\hline 3 & $\begin{array}{l}\text { Moral justifications have a focus on interpersonal relationships, } \\
\text { a sense of 'good-ness', and feelings such as empathy and } \\
\text { trust. Decisions are made with good motives and a prosocial } \\
\text { perspective of the world. }\end{array}$ & - Because he/she could get hurt. \\
\hline 4 & $\begin{array}{l}\text { Moral justifications start to incorporate a broader view of } \\
\text { morality; based on the compliance with rules, regulations } \\
\text { and standards that society has established to ensure social } \\
\text { order. }\end{array}$ & $\begin{array}{l}\text { - Because if everyone were to be } \\
\text { unfaithful, relationships would not } \\
\text { have any meaning. }\end{array}$ \\
\hline 5 & $\begin{array}{l}\text { Moral justifications are characterised by the capacity to } \\
\text { evaluate situations from various points of view to identify } \\
\text { values involved in the specific situation to make the fairest } \\
\text { decision. Protection of fundamental values and people's } \\
\text { rights is specific to this stage, even though these concepts } \\
\text { are expressed very concretely. }\end{array}$ & $\begin{array}{l}\text { - Because people work hard for their } \\
\text { things and we should respect their } \\
\text { belongings. }\end{array}$ \\
\hline
\end{tabular}

the ratings was .92 indicating high inter-rater reliabilty. Discrepancies were resolved by discussion and consensus.

Empathy: Empathy was measured using the Index of Empathy for Children and Adolescents (IECA, for participants aged 12 and over) (Bryant, 1982) and its adapted parent version, the Griffith Empathy Measure (GEM, for participants aged 11 and under) (Dadds et al., 2008). Both the IECA and GEM are general empathy questionnaires measuring an individual's understanding of other people's emotions. The IECA is a self-report questionnaire with 22 items using a yes/no format in the firstperson. In the GEM, the same questions are reworded in the third person format. For example the IECA item 'I get upset when I see an animal being hurt' is worded as 'My child gets upset when he/she sees an animal being hurt' in the GEM. The original version of the GEM is a 23-item questionnaire with a nine-point Likert scale. For the purpose of this study, we removed the item that differs between the two scales and used a yes/no format to make the scaling of the two questionnaires comparable. Therefore, items on both measures were scored on a dichotomous scale $(0=$ non-empathic response; $1=$ empathic response), with higher scores corresponding to higher levels of empathy. The IECA and the GEM have adequate validity and reliability and are well correlated (Bryant, 1982; Dadds et al., 2008).

Social adaptive skills: Social adaptive skills were assessed using the parent-report version of the Adaptive Behaviour Assessment System-2 (Harrison \& Oakland, 2003). Standardised scores on the Social scale were used in the current study as a measure of children's ability to communicate and behave appropriately in social interactions $(M=$ $100, S D=15)$.

Sociobehavioural problems: Sociobehavioural problems were measured using the parent-report version of the Child Behaviour Checklist (Achenbach \& Rescorla, 2001). The CBCL assesses internalising behaviours (anxiety, depression, somatic problems, thought problems) and externalising behaviours (social problems, attention problems, aggressive behaviour, rule-breaking behaviour). It has good reliability, as well as the power to discriminate between children who are and are not referred for a clinical assessment (Achenbach, 1991). Composite T-scores on the three-broadband scales (internalising, externalising and total problems) are reported $(M=50, S D=10)$. Scores on the rulebreaking behaviour scale $(M=50, S D=10)$ are also reported since previous studies in non-injured children have posited that failure to abide by moral guidelines is prominent in the rule-breaking 
TABLE 3

Means (SD) and Paired-Sample t-Tests Comparing Group Means on Main Measures

\begin{tabular}{lcccccc}
\hline & $\begin{array}{l}\text { Focal EBI } \\
\text { mean (SD) }\end{array}$ & $\begin{array}{l}\text { Control } \\
\text { mean (SD) }\end{array}$ & $\begin{array}{l}\text { Mean } \\
\text { difference }\end{array}$ & t-test & p-value & $\begin{array}{l}\text { Effect } \\
\text { size }\end{array}$ \\
\hline Demographic variables & & & & & & \\
Age & $12.9(2.2)$ & $12.9(2.2)$ & 0.0 & -0.65 & 0.528 & 0.03 \\
Parental educationa & $15.4(2.7)$ & $15.0(2.7)$ & 0.4 & 0.67 & 0.511 & 0.14 \\
General cognition & & & & & & \\
WASI IQ & $99.7(16.2)$ & $108.3(14.5)$ & 8.6 & -1.99 & 0.066 & 0.56 \\
Vocabulary & $50.0(11.9)$ & $55.9(12.2)$ & 5.9 & -1.75 & 0.102 & 0.49 \\
Matrix reasoning & $49.0(10.5)$ & $53.6(6.5)$ & 4.6 & -1.94 & 0.072 & 0.54 \\
Cognitive Flexibility & $10.3(2.3)$ & $11.6(1.8)$ & 1.3 & -1.50 & 0.162 & 0.62 \\
Social cognition & & & & & & \\
MR maturity & $23.5(6.1)$ & $28.3(6.2)$ & 4.8 & -2.93 & $0.011^{*}$ & 0.78 \\
Moral decision-making & $8.9(1.5)$ & $9.8(0.4)$ & 0.9 & -2.20 & $0.045^{*}$ & 0.94 \\
Empathy & $13.9(3.9)$ & $17.7(4.1)$ & 3.8 & -3.55 & $0.003^{* *}$ & 0.95 \\
Questionnaires & & & & & & \\
Rule-breaking behaviour (CBCL) & $56.7(7.5)$ & $53.1(4.3)$ & 3.6 & 1.63 & 0.125 & 0.61 \\
Externalising problems (CBCL) & $55.9(12.1)$ & $49.1(10.0)$ & 6.8 & 1.59 & 0.133 & 0.61 \\
Internalising problems (CBCL) & $60.9(8.9)$ & $54.3(10.3)$ & 6.6 & 1.64 & 0.124 & 0.69 \\
Total problems (CBCL) & $60.5(9.6)$ & $50.6(10.4)$ & 9.9 & 2.44 & $0.029^{*}$ & 0.99 \\
Social adaptive skills (ABAS) & $90.1(17.9)$ & $97.9(19.2)$ & 7.8 & -1.47 & 0.165 & 0.42 \\
\hline
\end{tabular}

${ }^{*} p<.05 ;{ }^{* *} p<.01$. ' Mean of mother's and father's education in years; ${ }^{b}$ Trail-Making Test Contrast Score between Number-Letter sequencing and Number-Letter switching.

behaviours that lead to criminality, violence and delinquent behaviour (Chudzik, 2007; Raaijmakers et al., 2005).

\section{Statistical Analysis}

Due to the exploratory nature of the study, the probability for type 1 error was set at .05 for each measure. Prior to all statistical analyses, data were examined for violations of the assumption of normality. The means and standard deviations for the different scores were calculated separately for the Focal EBI and control group and are presented in Table 3. In accordance with the matched control study design, paired t-tests were conducted to compare the mean differences between Focal EBI patients and their matched controls on sociocognitive measures, IQ, cognitive flexibility and parent questionnaire ratings (sociobehavioural problems and social adaptive skills). Prior to this decision, we performed non-parametric sensitivity analyses (Wilcoxon signed rank test) and obtained the same results as those generated with t-tests. We also performed sensitivity analyses by excluding the 8-year old patient and the main results did not change. Therefore, we report findings on the whole sample. Within group age differences were explored using a scatterplot to graphically compare MR maturity between the two groups, taking age into account. Proportions of individuals presenting mature MR levels (stage 3 and above) in both groups were compared using Mcnemar's test. Wilcoxon signed rank tests were used to evaluate between-group differences in MR stages. Bivariate correlations were performed to investigate the relationship between social cognition measures (MR maturity, moral decision-making, empathy), general cognition measures (IQ and cognitive flexibility) and more general indicators of social functioning: externalising problems (CBCL), internalising problems (CBCL), total problems (CBCL) and social adaptive skills (ABAS).

\section{Results}

The characteristics and individual scores on the So-Moral of the Focal EBI patients are presented in Table 1. No participants were excluded based on the IQ criterion. Means, standard deviations and paired sample t-tests for the main measures are presented in Table 3. As expected after matching, no significant differences were found for age and parental education. The focal EBI group performed significantly worse on all social cognition 


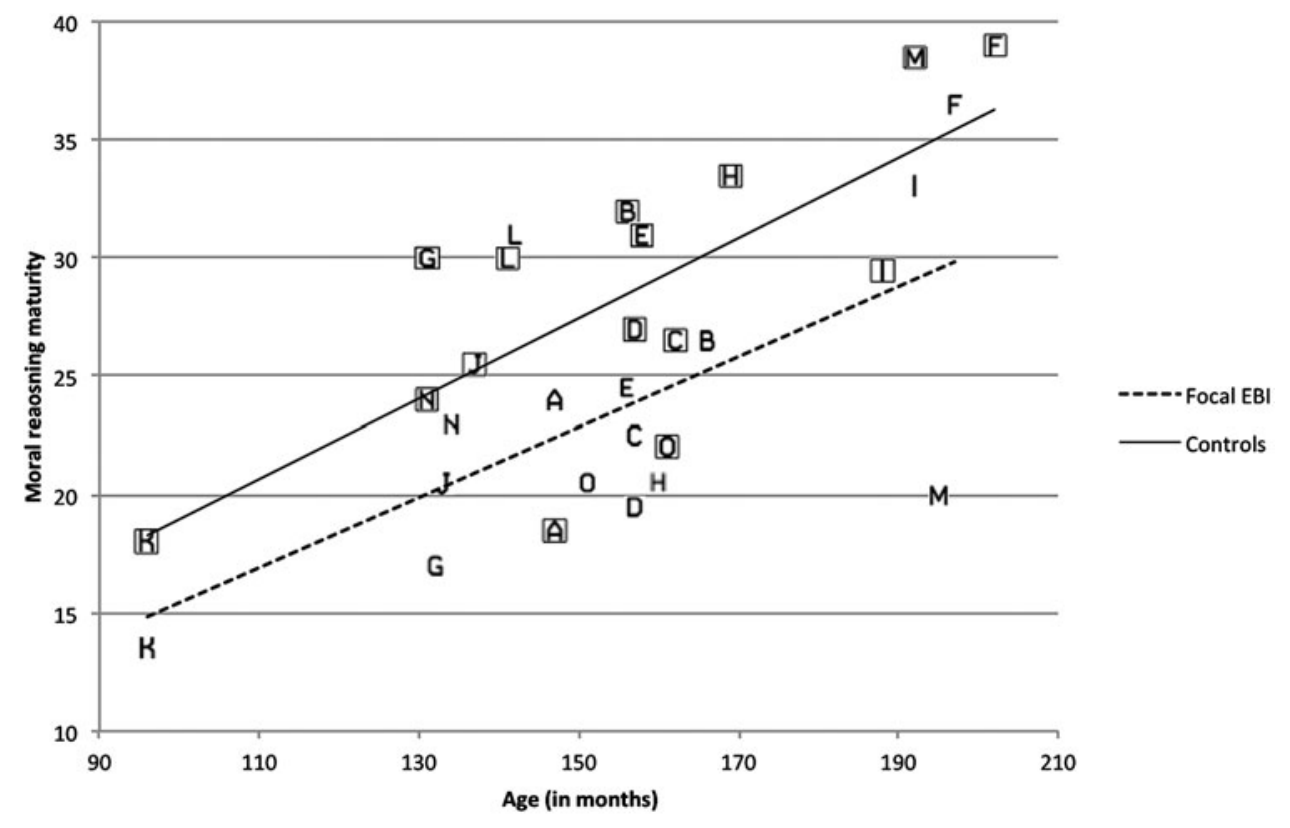

FIGURE 3

Regression lines and scatterplot of distribution of scores for MR maturity as assessed by the So-Moral for patients with focal EBI and controls across age. Focal EBI patients are identified by letters and their matched controls with the corresponding letter inside a square.

measures (MR, moral decision and empathy), whilst they did not differ from the control group on general cognition measures (IQ and cognitive flexibility). In terms of social functioning, only the CBCL Total Problems score differed significantly between groups. No differences were found for social adaptive skills (ABAS).

Figure 3 presents a scatterplot comparing MR maturity between the focal EBI and control groups across age. This reveals a strong correlation between MR and age in both Focal EBI $(r=.65, p$ $<.01)$ and control groups $(r=.73, p<.01)$. The graph further shows that whilst MR maturity score increases linearly with age in both groups, control participants almost systematically perform better than focal EBI across ages.

Mcnemar's test indicates that more Focal EBI patients perform at immature MR levels than controls $(p=.016)$. When the distribution of patients and control participants was compared across all five MR levels (see Table 4), controls had significantly higher levels of MR than Focal EBI patients $(z=-2.714, p=.007)$.

As shown in Table 5, empathy was significantly correlated with MR and decision-making in the focal EBI group.

\section{Discussion}

In the current study, social cognition and functioning were studied in a group of children and adolescents with frontotemporal lesions, with a particular interest in determining whether focal brain insults are associated with difficulties in MR during a critical period for social development. Our main results show that children with focal EBI have less mature MR in addition to displaying lower rates of moral decision-making and poorer empathy than their non-injured peers. Although these sociocognitive functions are distinct, they are interrelated and necessary foundations for adequate social functioning and they share common neural substrates (Bernhardt \& Singer, 2012; Sevinc \& Spreng, 2014). These results are discussed in detail below and links are provided on the complex interplay between these functions and their potential role in explaining outcomes after focal EBI.

Children with focal EBI provided significantly less mature moral justifications to realistic social dilemmas than their non-injured peers. They had a mean global stage of MR maturity that was one level (stage 2) lower than controls (stage 3). Our findings reflect both a mean group difference, as 
TABLE 4

Distribution of Participants According to MR Maturity Stage

\begin{tabular}{|c|c|c|c|c|c|}
\hline & \multicolumn{2}{|c|}{ Immature MR } & \multicolumn{3}{|c|}{ Mature MR } \\
\hline & Stage 1 & Stage 2 & Stage 3 & Stage 4 & Stage 5 \\
\hline Focal EBI & 1 & 10 & 3 & 1 & 0 \\
\hline Controls & 0 & 4 & 9 & 2 & 0 \\
\hline
\end{tabular}

Note: $M R=$ moral reasoning.

TABLE 5

Correlations Between Main Variables in the Focal EBI Group

\begin{tabular}{lccc}
\hline Variables & MR maturity & Moral decision-making & Empathy \\
\hline MR maturity & 1 & 0.47 & $0.56^{*}$ \\
Moral decision-making & 0.48 & 1 & $0.52^{*}$ \\
Empathy & $0.56^{*}$ & $0.52^{*}$ & 1 \\
WASI IQ & 0.49 & -0.05 & 0.17 \\
Cognitive Flexibility & 0.34 & 0.13 & 0.09 \\
Rule breaking behaviour & -0.37 & -0.39 & -0.47 \\
Externalising problems & -0.21 & -0.20 & -0.36 \\
Internalising problems & -0.18 & -0.24 & $-0.58^{*}$ \\
Total problems & -0.29 & -0.23 & $-0.53^{*}$ \\
Social adaptive skills & 0.20 & -0.11 & 0.43 \\
\hline
\end{tabular}

$* p<.05$.

Note: $M R=$ moral reasoning.

well as individual differences on MR. In fact, every patient with focal EBI had a mean score corresponding to an equivalent or lower stage of MR maturity than their matched controls. The majority $(11 / 15,73 \%)$ of patients with focal EBI reasoned at stage 2 or below on the So-Moral task. At these more 'immature' stages, individuals justify their responses to moral dilemmas based on egocentric concerns such as fear of punishment or personal gains (i.e., exchanging favours with others). They are able to recognise that different people may have different opinions about the way things are done, but their decision-making is ultimately driven from an egocentric perspective. In other words, the correct option is the one that is right for them (i.e., they are self-interested). In contrast, the majority of controls $(11 / 15,73 \%)$ reasoned at stage 3 or above, which marks the transition from an immature MR level (pre-conventional) to a mature MR level (conventional), according to moral development theories (Gibbs, 2010; Kohlberg, Levine, \& Hewer, 1983). At stage 3, individuals justify their actions with a focus on interpersonal relationships, a sense of 'goodness' and feelings such as empathy and trust. At this stage, decisions are made with externally oriented motives and a prosocial perspective. Reasoning is more flexible as the individual takes into account others' interests and/or social norms. One possible explanation for the difference in MR maturity identified between patients with focal EBI and controls is related to the notion of development of decentration; that is, the ability to shift away from a focus on the self towards attending to and interrelating of situational features or perspectives (Kaplan, 1989). Decentration develops during ontogenetic development in parallel with cognitive development, empathy and social opportunities (Kohlberg, 1984). It requires the integration of multiple pieces of information about causes and mental states, as well as the ability to consider conflicting emotions. Lower levels of MR after Focal EBI may thus reflect a broader cognitive impairment (i.e. executive functions, working memory), which may impede the process of decentration and reflect a failure or delay to reach a mature level of MR (stage 3 and above). Globally, our findings concord with traditional case reports (Anderson et al., 1999; Grattan \& Eslinger, 1992) and a previous study investigating MR in children with focal frontal lesions (Couper et al., 2002), which highlighted impairment in the acquisition of mature MR as a result 
of focal EBI. Importantly, the current results were obtained using an ecological visual task that limits the impact of confounding cognitive factors often impaired in clinical populations such as reading, attentional and working memory skills (Dooley et al., 2010) and assesses reasoning during everyday moral dilemmas. Longitudinal studies would be useful to track the evolution of MR differences and verify whether these delays persist or worsen in the long-term after EBI (Beauchamp \& Anderson, 2013; Janusz, Kirkwood, Yeates, \& Taylor, 2002).

In addition to relying on less mature MR, children with focal EBI also provided significantly fewer moral responses, which were determined by the number of socially appropriate decisions taken in the dilemmas presented. In light of this, it is possible that children with focal EBI may be more inclined to engage in behaviours that do not comply with social expectations. Both cognitive and affective functions contribute to moral decision-making (Rosen, Brand, \& Kalbe, 2016); the lower levels of MR and empathy found in the focal EBI group may thus provide an explanation for differences in moral decision-making. A previous study in TBI identified a distinction between knowing and understanding in the moral domain (Beauchamp et al., 2013). That is, children with TBI were able to identify the correct moral responses (moral decision-making), but did not have the capacity to provide mature reasoning to support their decision, indicating a lack of comprehension of the social consequences of a given decision. In the current study, we found significant differences on both moral indices (moral decisionmaking and MR maturity), highlighting difficulties in both the knowing and understanding facets of moral dilemmas. However, caution in drawing conclusions is advised and a larger sample of focal EBI is necessary to confirm these findings considering overall mean differences were relatively small. Studies of social behaviour in naturalistic settings could also provide further insights into the moral decision-making of these children in real-life situations.

Children with focal EBI also exhibited poorer empathy compared to control participants. This finding provides for the first time quantitative evidence of previous anecdotal accounts of lack of empathy in case studies of focal EBI (Anderson et al., 1999; Grattan \& Eslinger, 1992). Numerous studies have suggested that the lower empathy scores of patients with frontal brain injury may be related to cognitive flexibility (Grattan, Bloomer, Archambault, \& Eslinger, 1994; Grattan \& Eslinger, 1989; Shamay-Tsoory, Tomer, Berger, \& Aharon-Peretz, 2003; Shamay-Tsoory, Tomer,
Goldsher, Berger, \& Aharon-Peretz, 2004). However, in the present study, no correlation was found between empathy and cognitive flexibility in the focal EBI group. The inclusion of multiple cognitive flexibility measures in future studies would be important since flexibility is hypothesised to develop in a domain-specific fashion as children gain task-specific skills and knowledge (Deak \& Wiseheart, 2015; Luwel, Verschaffel, Onghena, \& De Corte, 2003). Empathy and morality share common neural substrates in the social brain and are both supported by a diffuse network that includes several frontotemporolimbic structures (Bernhardt \& Singer, 2012; Pascual, Rodrigues, \& GallardoPujol, 2013; Sevinc \& Spreng, 2014). The poorer empathy, MR and moral decision-making found in the Focal EBI patients may thus be attributable to disruptions of the frontotemporal circuitry underlying social cognition, as shown in studies of adults with focal lesions (see Hillis, 2014 for a review). Given the evidence of phases in development of both MR and emotion recognition (Tonks et al., 2009), it is possible that an early brain insult to frontal or temporal regions may disrupt normal acquisition of such sociocognitive functions and potentially cause delayed effects of deficits as social demands increase.

As expected, children with focal EBI had more sociobehavioural problems than controls, although the standardised scores did not reach the clinical threshold. Patients with focal EBI had more internalising than externalising problems, in line with a previous study investigating psychopathological profiles of children with focal EBI (Duval, Braun, Daigneault, \& Montour-Proulx, 2002). Elevated scores on the internalisation subscale could be attributable to physical illness in these children and emotional response to a threatening medical condition. Despite the fact that no significant differences were found on the other CBCL scales or for social adaptive skills (ABAS), children with frontotemporal lesions had consistently lower scores than their matched counterparts.

Finally, whilst the study methodology did not include a full cognitive protocol, these preliminary results suggest that social cognition may be more vulnerable to focal frontotemporal brain damage than general cognitive functions. These differential findings make intuitive sense in that functions subsumed by discrete lateralised brain regions may have greater capacity for reorganisation than those dependent on more diffuse neural networks, such as social cognition (Anderson et al., 2011). They also converge with studies of TBI, which highlight impairments in emotion processing and MR despite adequate intellectual and/or executive functioning (Anderson, Barrash, Bechara, \& Tranel, 
2006; Martins, Faisca, Esteves, Muresan, \& Reis, 2012; Tousignant et al., 2016). Future work could seek to answer the question of general cognitive vs. sociocognitive deficits via more elaborate neuropsychological test batteries and a more ecological approach to the assessment of executive functions as suggested by Burgess et al. (2006). Also, given that the effect sizes for IQ and EF remain substantial, further studies could test the hypothesis that focal EBI results in a developmental delay that affects intellectual, executive and sociocognitive functions and leads to more sociobehavioural problems in accordance with the Socio-Cognitive Integration of Abilities Model (Beauchamp \& Anderson, 2010).

\section{Clinical Implications}

Children with focal EBI may have impaired social cognitive skills that a clinician might not suspect based on assessment of general cognitive ability and behaviour alone. The differences in social cognitive functioning that we identified are subtle and difficult to detect, yet they may potentially impact the quality of children's social life. The challenge for practitioners working with children who sustain focal EBI will be to identify those who are in need of additional intervention to target delay or deficits in social cognitive functions. In the future, the development of further ecological and standardised measures of social cognition may provide avenues for specifically assessing these functions in children with EBI.

\section{Strengths and Limitations}

Whilst the current study is the first to directly investigate different aspects of social cognition in a group of children with focal EBI, the statistical power of our analyses was limited by the small sample size. This is most obvious with some of the paired comparisons that were non-significant, but had medium effect sizes, such as IQ and EF. Still, statistically significant differences were found in some of the proposed analyses. The inclusion of patients with a history of seizure may have contributed to the findings, however, those with severe and uncontrolled epilepsy were excluded. The sample size and heterogeneity of lesions precluded examination of the individual contribution of lesion variables to outcome. Further examination of the effects of lesion size, type, location and onset with a larger group is warranted. Also, the inclusion of a non-cerebral patient control group (e.g. chronic asthma) could be insightful in controlling for the effects of hospital admission and chronic illness.
Despite these limitations, the study has several strengths. One of them is the use of an innovative MR assessment measure adapted for children and adolescents and designed to minimise methodological flaws associated with traditional MR tasks (Dooley et al., 2010). The combined use of both direct and indirect measures helped gain a better understanding of social functioning after focal EBI, though a direct measure of empathy was not available. This highlights the need for development of more innovative measurement approaches for directly assessing sociocognitive functions. The selection of demographically matched control participants on an individual basis represents a strength that allowed for paired comparisons. Participants were paired on age, sex, and parental education, in an attempt to eliminate potential sources of extraneous variation.

\section{Conclusions}

In summary, our results suggest that early brain insult involving focal pathology in frontotemporal regions may have an adverse effect on social cognition and behaviour. MR appears to be particularly vulnerable to such brain damage, as highlighted by lower MR maturity levels in youth with focal EBI. The variability in lesion locations highlights the diversity of frontotemporal damage likely to be associated with socio-cognitive vulnerability. Nonetheless, individual cases within this study illustrate the potential for adequate sociocognitive functioning and social behaviour despite evidence of structural damage, and suggest that multiple factors need to be taken into account in identifying children with focal EBI at risk for social dysfunction.

\section{Acknowledgements}

We gratefully acknowledge the input of Miguel Chagnon for statistical analysis.

\section{Financial Support}

This work was supported by the Natural Sciences and Engineering Council of Canada (\#3865272010).

\section{Conflict of Interest}

None.

\section{Ethical Standards}

The authors assert that all procedures contributing to this work comply with the ethical standards of the relevant national and institutional committees 
on human experimentation and with the Helsinki Declaration of 1975, as revised in 2008.

\section{References}

Achenbach, T.M. (1991). Manual for the Child Behavior Checklist/4-18 and 1991 Profile. Burlington: University of Vermont.

Achenbach, T.M., \& Rescorla, L.A. (2001). Manual for ASEBA school-age forms \& profiles. Burlington, VT: University of Vermont, Research Center for Children, Youth, \& Families.

Adolphs, R. (2009). The social brain: Neural basis of social knowledge. Annual Review of Psychology, 60(1), 693-716.

Anderson, S.W., Barrash, J., Bechara, A., \& Tranel, D. (2006). Impairments of emotion and real-world complex behavior following childhood- or adult-onset damage to ventromedial prefrontal cortex. Journal of the International Neuropsychological Society, 12(2), 224-235.

Anderson, S.W., Bechara, A., Damasio, H., Tranel, D., \& Damasio, A.R. (1999). Impairment of social and moral behavior related to early damage in human prefrontal cortex. Nature Neuroscience, 2(11), 10321037.

Anderson, V., Catroppa, C., Morse, S., Haritou, F., \& Rosenfeld, J. (2005). Functional plasticity or vulnerability after early brain injury?. Pediatrics, 116(6), 1374-1382.

Anderson, V., Godfrey, C., Rosenfeld, J.V., \& Catroppa, C. (2012). 10 years outcome from childhood traumatic brain injury. International Journal of Developmental Neuroscience, 30(3), 217-224.

Anderson, V., Gomes, A., Greenham, M., Hearps, S., Gordon, A., Rinehart, N. ... Mackay, M. (2014). Social competence following pediatric stroke: Contributions of brain insult and family environment. Social Neuroscience, 9(5), 471-483.

Anderson, V., Spencer-Smith, M., \& Wood, A. (2011). Do children really recover better? Neurobehavioural plasticity after early brain insult. Brain, 134(Pt 8), 2197-2221.

Aram, D., \& Ekelman, L. (1986). Cognitive profiles of children with early onset unilateral lesions. Developmental Neuropsychology, 2(3), 155-172.

Bahia, V.S., Takada, L.T., Caixeta, L., Lucato, L.T., Porto, C.S., \& Nitrini, R. (2013). Prefrontal damage in childhood and changes in the development of personality: A Case report. Dementia \& Neuropsychologia, 7(1), 132-125.

Bates, E., Thal, D., Trauner, D., Fenson, J., Aram, D., Eisele, J., \& Nass, R. (1997). From first words to grammar in children with focal brain injury. Developmental Neuropsychology, 1, 187-202.

Beauchamp, M.H., \& Anderson, V. (2010). SOCIAL: An integrative framework for the development of social skills. Psychological Bulletin, 136(1), 39-64.
Beauchamp, M.H., \& Anderson, V. (2013). Cognitive and psychopathological sequelae of pediatric traumatic brain injury. In O. Dulac, S. Di Mauro, \& M. Lassonde (Eds.), Handbook of clinical pediatric neurology (pp. 913-920). Amsterdam: Elsevier.

Beauchamp, M.H., \& Dooley, J.J. (2012). Administration and coding manual sociomoral reasoning aptitude level task (so moral). Canada: ABCs Laboratory.

Beauchamp, M.H., Dooley, J.J., \& Anderson, V. (2013). A preliminary investigation of moral reasoning and empathy after traumatic brain injury in adolescents. Brain Injury, 27(7-8), 896-902.

Bernhardt, B.C., \& Singer, T. (2012). The neural basis of empathy. Annual Review of Neuroscience, 35, 1-23.

Bigler, E.D., Yeates, K.O., Dennis, M., Gerhardt, C.A., Rubin, K.H., Stancin, T. ... Vannatta, K. (2013). Neuroimaging and social behavior in children after traumatic brain injury: Findings from the Social Outcomes of Brain Injury in Kids (SOBIK) study. NeuroRehabilitation, 32(4), 707-720.

Blakemore, S.J. (2008). Development of the social brain during adolescene. Quarterly Journal of Experimental Psychology, 61(1), 40-49.

Blakemore, S.J., \& Frith, U. (2004). How does the brain deal with the social world?. Neuroreport, 15(1), 119128 .

Boes, A.D., Grafft, A.H., Joshi, C., Chuang, N.A., Nopoulos, P., \& Anderson, S.W. (2011). Behavioral effects of congenital ventromedial prefrontal cortex malformation. BMC Neurology, 11(1), 151.

Bryant, B.K. (1982). An index of empathy for children and adolescent. Child Development, 53, 413-425.

Burgess, P.W., Alderman, N., Forbes, C., Costello, A., Coates, L.M., Dawson, D.R. ... Channon, S. (2006). The case for the development and use of "ecologically valid" measures of executive function in experimental and clinical neuropsychology. Journal of the International Neuropsychological Society, 12(2), 194-209.

Burnett, S., \& Blakemore, S.J. (2009). The development of adolescent social cognition. Annals of the New York Academy of Sciences, 1167, 51-56.

Cacioppo, J.T., \& Decety, J. (2011). Social neuroscience: Challenges and opportunities in the study of complex behavior. Annals of the New York Academy of Sciences, 1224, 162-173.

Carey, M.E., Barakat, L.P., Foley, B., Gyato, K., \& Phillips, P.C. (2001). Neuropsychological functioning and social functioning of survivors of pediatric brain tumors: Evidence of nonverbal learning disability. Child Neuropsychology, 7(4), 265-272.

Chilosi, A.M., Cipriani, P., Pecini, C., Brizzolara, D., Biagi, L., Montanaro, D. . . Cioni, G. (2008). Acquired focal brain lesions in childhood: Effects on development and reorganization of language. Brain and Language, 106(3), 211-225.

Chudzik, L. (2007). Moral judgment and conduct disorder intensity in adolescents involved in delinquency: Matching controls by school grade. Psychological Reports, 101(1), 221-236. 
Colby, A., \& Kohlberg, L. (1987). The measurement of moral judgment. New York: Cambridge University Press.

Couper, E., Jacobs, R., \& Anderson, V. (2002). Adaptive behaviour and moral reasoning in children with frontal lobe lesions. Brain Impairment, 3, 105-113.

Dadds, M.R., Hunter, K., Hawes, D.J., Frost, A.D., Vassallo, S., Bunn, P. . . . Masry, Y.E. (2008). A measure of cognitive and affective empathy in children using parent ratings. Child Psychiatry and Human Development, 39(2), 111-122.

Deak, G.O., \& Wiseheart, M. (2015). Cognitive flexibility in young children: General or task-specific capacity?. Journal of Experimental Child Psychology, 138, 31-53.

Delis, D.C., Kaplan, E., \& Kramer, J.H. (2001). DelisKaplan executive function system (D-KEFS): Examiner manual. San Antonio, TX: The Psychological Corporation.

Dennis, M., Simic, N., Gerry Taylor, H., Bigler, E.D., Rubin, K., Vannatta, K. ... Yeates, K.O. (2012). Theory of mind in children with traumatic brain injury. Journal of the International Neuropsychological Society, 18(5), 908-916.

Dooley, J.J., Beauchamp, M.H., \& Anderson, V. (2010). The measurement of sociomoral reasoning in adolescents with traumatic brain injury: A pilot investigation. Brain Impairment 11(2), 152-161.

Duval, J., Braun, C. M., Daigneault, S., \& MontourProulx, I. (2002). Does the child behavior checklist reveal psychopathological profiles of children with focal unilateral cortical lesions?. Applied Neuropsychology, 9(2), 74-83.

Duval, J., Braun, C.M., Montour-Proulx, I., Daigneault, S., Rouleau, I., \& Begin, J. (2008). Brain lesions and IQ: Recovery versus decline depends on age of onset. Journal of Child Neurology, 23(6), 663668.

Eslinger, P.J., Flaherty-Craig, C.V., \& Benton, A.L. (2004). Developmental outcomes after early prefrontal cortex damage. Brain and Cognition, 55(1), 84-103.

Frith, U., \& Frith, C. (2010). The social brain: Allowing humans to boldly go where no other species has been. Philosophical Transactions of the Royal Society of London, 365(1537), 165-176.

Fuemmeler, B.F., Elkin, T.D., \& Mullins, L.L. (2002). Survivors of childhood brain tumors: Behavioral, emotional, and social adjustment. Clinical Psychology Review, 22(4), 547-585.

Galvin, J., Hewish, S., Rice, J., \& Mackay, M.T. (2011). Functional outcome following paediatric stroke. Developmental Neurorehabilitation, 14(2), 67-71.

Ganesalingam, K., Yeates, K.O., Sanson, A., \& Anderson, V. (2007). Social problem-solving skills following childhood traumatic brain injury and its association with self-regulation and social and behavioural functioning. Journal of Neuropsychology, 1(Pt 2), 149-170.
Garland, T. (2005). Test review : WASI. Journal of Occupational Psychology, Employment and Disability, 7(2), 130-135.

Gibbs, J.C. (2010). Moral development \& reality: Beyond the theories of Kohlberg and Hoffman. (2nd Ed.). Boston: Allyn \& Bacon.

Grattan, L.M., Bloomer, R.H., Archambault, F.X., \& Eslinger, P.J. (1994). Cognitive flexibility and empathy after frontal lobe lesion. Neuropsychiatry, Neuropsychology, \& Behavioral Neurology, 7, 251-259.

Grattan, L.M., \& Eslinger, P.J. (1989). Higher cognition and social behavior: Changes in cognitive flexibility and empathy after cerebral lesions. Neuropsychology, 3, 175-185.

Grattan, L.M., \& Eslinger, P.J. (1992). Long-term psychological consequences of childhood frontal lobe lesion in patient DT. Brain and Cognition, 20(1), 185-195.

Greene, J.D., Nystrom, L.E., Engell, A.D., Darley, J.M., \& Cohen, J.D. (2004). The neural bases of cognitive conflict and control in moral judgment. Neuron, 44(2), 389-400.

Greenham, M., Spencer-Smith, M.M., Anderson, P.J., Coleman, L., \& Anderson, V.A. (2010). Social functioning in children with brain insult. Frontiers in Human Neuroscience, 4(22), 1-10.

Haidt, J. (2001). The emotional dog and its rational tail: A social intuitionist approach to moral judgment. Psychological Review, 108(4), 814-834.

Harrison, P., \& Oakland, T. (2003). Adaptive Behavior Assessment System (2nd Edn.). San Antonio, Texas: The Psychological Corporation.

Hetherington, R., Tuff, L., Anderson, P., Miles, B., \& deVeber, G. (2005). Short-term intellectual outcome after arterial ischemic stroke and sinovenous thrombosis in childhood and infancy. Journal of Child Neurology, 20(7), 553-559.

Hillis, A.E. (2014). Inability to empathize: Brain lesions that disrupt sharing and understanding another's emotions. Brain, 137(4), 981-997.

Hogan, A.M., Kirkham, F.J., \& Isaacs, E.B. (2000). Intelligence after stroke in childhood: Review of the literature and suggestions for future research. Journal of Child Neurology, 15(5), 325-332.

Janusz, J.A., Kirkwood, M.W., Yeates, K.O., \& Taylor, H.G. (2002). Social problem-solving skills in children with traumatic brain injury: Long-term outcomes and prediction of social competence. Child Neuropsychology, 8(3), 179-194.

Jernigan, T.L., Baare, W.F., Stiles, J., \& Madsen, K.S. (2011). Postnatal brain development: Structural imaging of dynamic neurodevelopmental processes. Progress in Brain Research, 189, 77-92.

Jolliffe, D., \& Farrington, D.P. (2004). Empathy and offending: A systematic review and meta-analysis. Agression and Violent Behavior, 9(5), 441-476.

Kaplan, M.F. (1989). Information integration in moral reasoning: Conceptual and methodological implications. In J.R.N. Eisenberg, \& E. Staub (Eds.), Social 
and moral values: Individual and societal perspectives (pp. 117-135). Hillsdale, NJ: Lawrence Erlbaum Associates.

Kohlberg, L. (1981). The meaning and measurement of moral development. Worcester, Mass.: Clark University Press.

Kohlberg, L. (1984). The psychology of moral development. San Francisco, CA: Harper \& Row.

Kohlberg, L., Levine, C., \& Hewer, A. (1983). Moral stages: A current formulation and a response to critics. New York: Karger.

Lo, W., Gordon, A., Hajek, C., Gomes, A., Greenham, M., Perkins, E. ... Mackay, (2014). Social competence following neonatal and childhood stroke. International Journal of Stroke, 9(8), 10371044.

Luwel, K., Verschaffel, L., Onghena, P., \& De Corte, E. (2003). Strategic aspects of numerosity judgment: The effect of task characteristics. Experimental Psychology, 50(1), 63-75.

Martins, A.T., Faisca, L.M., Esteves, F., Muresan, A., \& Reis, A. (2012). Atypical moral judgment following traumatic brain injury. Judgment and Decision Making, 7(4), 478-487.

Pascual, L., Rodrigues, P., \& Gallardo-Pujol, D. (2013). How does morality work in the brain? a functional and structural perspective of moral behavior. Frontiers in Integrative Neuroscience, 7(65), 65.

Raaijmakers, Q.A.W., Engels, R.C.M.E., \& Van Hoof, A. (2005). Delinquency and moral reasoning in adolescence and young adulthood. International Journal of Behavioral Development, 29(3), 247-258.

Rosema, S., Crowe, L., \& Anderson, V. (2012). Social function in children and adolescents after traumatic brain injury: A systematic review 1989-2011. Journal of Neurotrauma, 29(7), 1277-1291.

Rosen, J.B., Brand, M., \& Kalbe, E. (2016). Empathy mediates the effects of age and sex on altruistic moral decision making. Frontiers in Behavioral Neuroscience, 10, 67 .

Schonert-Reichl, K.A. (1999). Relations of peer acceptance, friendship adjustment, and social behavior to moral reasoning during early adolescence. Journal of Early Adolescence, 19, 249-279.

Sevinc, G., \& Spreng, R.N. (2014). Contextual and perceptual brain processes underlying moral cognition: A quantitative meta-analysis of moral reasoning and moral emotions. PLoS One, 9(2), e87427.

Shamay-Tsoory, S.G., Tomer, R., Berger, B.D., \& Aharon-Peretz, J. (2003). Characterization of empathy deficits following prefrontal brain damage: The role of the right ventromedial prefrontal cortex. Journal of Cognitive Neuroscience, 15(3), 324337.

Shamay-Tsoory, S.G., Tomer, R., Goldsher, D., Berger, B.D., \& Aharon-Peretz, J. (2004). Impairment in cognitive and affective empathy in patients with brain lesions: Anatomical and cognitive correlates.
Journal of Clinical and Experimental Neuropsychology, 26(8), 1113-1127.

Snodgrass, C., \& Knott, F. (2006). Theory of mind in children with traumatic brain injury. Brain Injury, 20(8), 825-833.

Stiles, J., \& Jernigan, T.L. (2010). The basics of brain development. Neuropsychology Review, 20(4), 327348 .

Stiles, J., Reilly, J., Paul, B., \& Moses, P. (2005). Cognitive development following early brain injury: Evidence for neural adaptation. Trends in Cognitive Sciences, 9(3), 136-143.

Stiles, J., Stern, C., Appelbaum, M., Nass, R., Trauner, D., \& Hesselink, J. (2008). Effects of early focal brain injury on memory for visuospatial patterns: Selective deficits of global-local processing. Neuropsychology, 22(1), 61-73.

Tonks, J., Slater, A., Frampton, I., Wall, S. E., Yates, P., \& Williams, W.H. (2009). The development of emotion and empathy skills after childhood brain injury. Developmental Medicine and Child Neurology, 51(1), 8-16.

Tonks, J., Williams, W.H., Frampton, I., Yates, P., \& Slater, A. (2007). Reading emotions after child brain injury: A comparison between children with brain injury and non-injured controls. Brain Injury, 21(7), 731-739.

Tousignant, B., Jackson, P.L., Massicotte, E., Beauchamp, M.H., Achim, A.M., Vera-Estay, E. ... Sirois, K. (2016). Impact of traumatic brain injury on social cognition in adolescents and contribution of other higher order cognitive functions. Neuropsychological Rehabilitation, 10, $1-19$.

Turiel, E. (1983). The development of social knowledge: Morality and convention. Cambridge: Cambridge University Press.

Turkstra, L.S., Dixon, T.M., \& Baker, K.K. (2004). Theory of Mind and social beliefs in adolescents with traumatic brain injury. NeuroRehabilitation, 19(3), 245-256.

Turkstra, L.S., McDonald, S., \& DePompei, R. (2001). Social information processing in adolescents: Data from normally developing adolescents and preliminary data from their peers with traumatic brain injury. Journal of Head Trauma Rehabilitation, 16(5), 469-483.

Vera-Estay, E., Beauchamp, M., \& Dooley, J. (2014). Cognitive underpinnings of moral reasoning in adolescence: The contribution of executive functions. Journal of Moral Education, 44(1), 17-33.

Vera-Estay, E., Seni, A.G., Champagne, C., \& Beauchamp, M.H. (2016). All for one: Contributions of age, socioeconomic factors, executive functioning, and social cognition to moral reasoning in childhood. Frontiers in Psychology, 7, 227

Wechsler, D. (1999). Wechsler Abbreviated Scale of Intelligence (WASI). San Antonio, TX: Harcourt Assessment. 
Yeates, K.O., Bigler, E.D., Dennis, M., Gerhardt, C.A., Rubin, K.H., Stancin, T. . . Vannatta, K. (2007). Social outcomes in childhood brain disorder: A heuristic integration of social neuroscience and developmental psychology. Psychological Bulletin, 133(3), 535-556.
Yeates, K.O., Swift, E., Taylor, H.G., Wade, S.L., Drotar, D., Stancin, T., \& Minich, , N. (2004). Short- and long-term social outcomes following pediatric traumatic brain injury. Journal of the International Neuropsychological Society, 10(3), 412426. 